BIS WORKING PAPERS

No. 77 - October 1999

\title{
PERCEIVED CENTRAL BANK INTERVENTION AND MARKET EXPECTATIONS: AN EMPIRICAL STUDY OF THE YEN/DOLLAR EXCHANGE RATE, 1993-96
}

\author{
by \\ Gabriele Galati and William Melick
}

BANK FOR INTERNATIONAL SETTLEMENTS

Monetary and Economic Department

Basel, Switzerland 
BIS Working Papers are written by members of the Monetary and Economic Department of the Bank for International Settlements, and from time to time by other economists, and are published by the Bank. The papers are on subjects of topical interest and are technical in character. The views expressed in them are those of their authors and not necessarily the views of the BIS.

Copies of publications are available from:

Bank for International Settlements

Information, Press \& Library Services

CH-4002 Basel, Switzerland

Fax: +41 61 / 2809100 and +4161 / 2808100

This publication is available on the BIS website (www.bis.org).

(C) Bank for International Settlements 1999.

All rights reserved. Brief excerpts may be reproduced or translated provided the source is stated. 


\title{
BIS WORKING PAPERS
}

No. 77 - October 1999

\section{PERCEIVED CENTRAL BANK INTERVENTION AND MARKET EXPECTATIONS: AN EMPIRICAL STUDY OF THE YEN/DOLLAR EXCHANGE RATE, 1993-96}

by

Gabriele Galati and William Melick*

\begin{abstract}
This paper uses a new data set, based on Reuters news articles, to capture intervention that is perceived by FX traders and probability density functions (PDFs) estimated from option data to describe market expectations. We find that, between September 1993 and April 1996, traders viewed the Bank of Japan as responding mainly to deviations of the exchange rate from what they considered to be some implicit target levels. On the other hand, the Federal Reserve was viewed to have mainly intervened when market conditions seemed most conducive to a successful intervention. We find that perceived intervention had no statistically significant effect on the exchange rate level and on the skewness of the PDFs. We also present evidence that, on average, perceived intervention increased traders' uncertainty about future exchange rate movements.
\end{abstract}

* Gabriele Galati is with the Bank for International Settlements and William Melick with Kenyon College, Ohio.

We wish to thank Adrian Coghlan for helping to build the data set on intervention from Reuters articles, Florence Béranger for excellent research assistance, Kevin Chang, Rasmus Fatum, Frank Smets and seminar participants at the BIS and the ECB for helpful comments, Tomislav Minic for editorial suggestions and Stephan Arthur for overseeing the publication. 



\section{Contents}

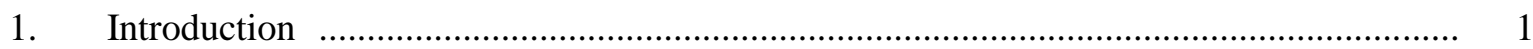

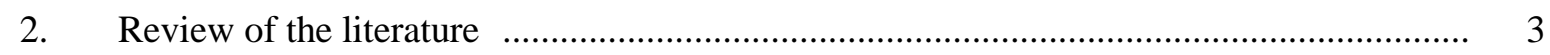

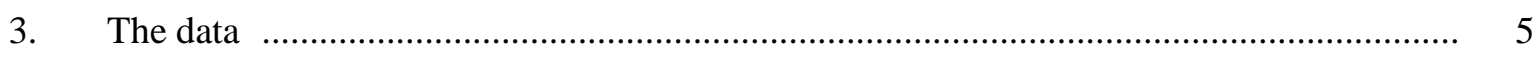

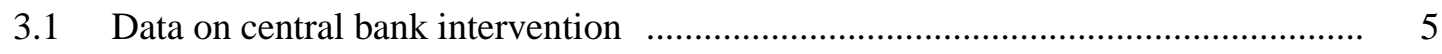

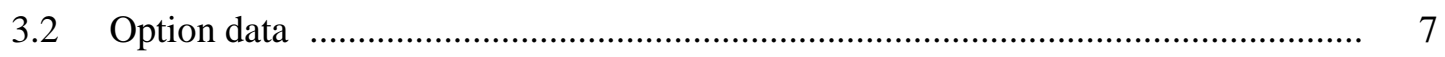

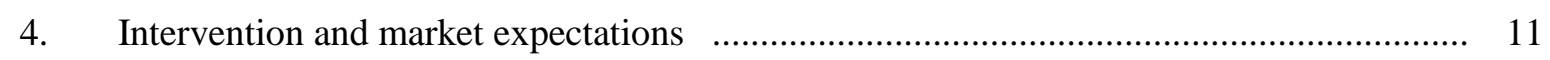

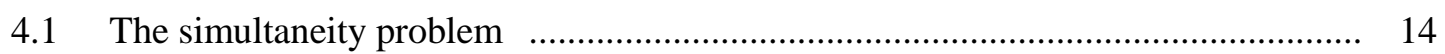

4.2 Estimates of a reaction function for the Federal Reserve and the Bank of Japan $\ldots \quad 15$

4.3 The effect of intervention on market expectations …......................................... 17

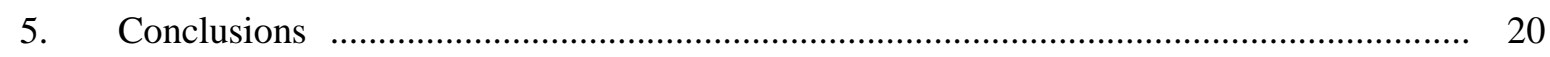

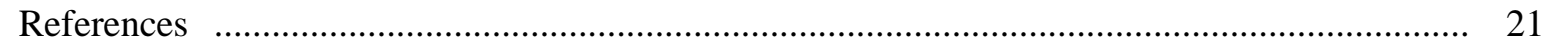





\section{Introduction}

This paper presents empirical evidence on the relationship between central bank intervention that is perceived by traders and reported in the press and market expectations of the daily yen/dollar exchange rate. Over the past years, a number of studies have analysed the effect of intervention on the exchange rate level as well as on the instantaneous and expected volatility of the exchange rate of the yen/dollar, the mark/dollar and other exchange rates. The results are generally mixed and depend on both the sample period being investigated and the intervention strategies being used.

This paper provides further evidence on this issue in four ways. First, it focuses not only on the expected level and variance of the exchange rate, but on the entire distribution of expected exchange rates, which is derived from option prices. The moments of this distribution allow a more complete characterisation of market sentiment. Second, this paper uses a new data set on intervention episodes perceived by market participants, which is based on Reuters reports. This data set is more comprehensive than the data sets based on newspaper articles that have been used in the literature. Third, this paper uses a more comprehensive data set of "news" about macroeconomic variables that helps to distinguish the effect of intervention from that of the arrival of other relevant news. Finally, it also looks at two directions of causality of the relationship between intervention and market expectations. We first examine the reaction function of monetary authorities and estimate how changes in the moments of the expected distribution of future exchange rates affect the likelihood of central bank intervention. We then investigate the effect of intervention on the moments, taking account of the fact that intervention and market expectations are determined simultaneously.

In this paper, the empirical probability density functions (PDFs) of future yen/dollar rates are estimated using risk reversals and at-the-money implied volatilities of one-month OTC options. ${ }^{1}$ We use measures of the moments of these distributions - the mean, variance, skewness and kurtosis - to describe the state of market conditions on a particular day. If we consider the yen/dollar exchange rate, the mean of the PDF is the traders' average expectation of the yen/dollar rate one month ahead, i.e. the one-month forward rate. The second moment of the PDF, the variance of the expected exchange rate, can be used to describe how uncertain market participants are on a specific day about the yen/dollar exchange rate that will prevail over the near future. Skewness can be interpreted as a measure of market participants' balance of risks between a much stronger or a much weaker dollar with respect to the yen around the expected future exchange rate. The fourth moment, kurtosis, measures how "fat" the tails of a PDF are and indicates the likelihood that the market attributes to very large exchange rate movements in either direction in the near future. The higher the probability that the market assigns to

1 In this paper, the exchange rate is defined as yen per dollar. 
such an extreme change (in either direction) on a particular day, the higher the kurtosis of the PDF on that day.

It should be stressed that this study focuses on intervention that is perceived by market participants, which may be different from actual intervention. The results presented in the paper may therefore look different if, instead of press report data, actual intervention figures were used. However, it is plausible that the former are relevant in influencing market expectations of future exchange rate movements.

This paper looks at the period from 13 September 1993 to 23 April 1996, one in which all central bank intervention that was perceived in the yen/dollar market was directed at supporting the dollar. ${ }^{2}$ For the purpose of this paper, central bank interventions are defined as transactions intended to influence the level of the exchange rate. This definition therefore excludes transactions such as those aimed at altering the currency composition of the central bank's foreign exchange portfolio.

Our results suggest that, during the period 1993-96, market participants viewed the Bank of Japan and the Federal Reserve as following substantially different intervention strategies. The Bank of Japan was seen to have responded mainly to deviations of the spot exchange rate from what traders perceived as implicit target ranges. By contrast, traders viewed the Federal Reserve as intervening mainly when market conditions were most conducive to a successful intervention, i.e. when the dollar was appreciating and market views were tilted in favour of a much stronger dollar. We also find that neither of the two central banks was seen on average to have intervened as a response to a rise in market uncertainty.

Similarly to some of the findings in the literature, our regression analysis suggests that, on average, perceived intervention in support of the dollar had no statistically significant effect on the forward rate (the mean of the PDF) during the period under review. We also find that, between September 1993 and April 1996, the existence of a market perception of central bank intervention directed at the yen/dollar exchange rate was associated with a higher variance of future spot rates. This result indicates that, on average, perceived central bank intervention was followed by an increase in uncertainty in the market about future exchange rate movements. This is in line with findings of other studies.

Consistent with our results for the forward rate, we find that, on average, perceived intervention did not have a significant effect on the skewness. Hence, following intervention in support of the dollar, market participants did not change the weight that they put on a much stronger rather than a much weaker dollar with respect to the forward rate.

The remainder of the paper is organised as follows. Section 2 reviews the main contributions to the literature on the effect of central bank intervention. In Section 3, we describe our intervention data and

2 The sample period is dictated by the availability of option data necessary to estimate the PDFs. 
the option data that were used to estimate the empirical PDFs. In Section 4, we first estimate reaction functions for the Federal Reserve and the Bank of Japan that relate intervention to past market conditions. We then analyse the impact of intervention on market expectations. Section 5 concludes.

\section{Review of the literature}

The literature on the effect of intervention in foreign exchange markets is extensive. This section reviews some of the main contributions - for a comprehensive survey, refer to Edison (1993). In the 1980s and early 1990s, attention focused on the effect of sterilised intervention on the level of the exchange rate and on the channels through which it works. The results on the effectiveness of intervention are mixed and depend on which exchange rate is analysed, what sample period is studied and the intervention strategy that was used.

In an influential paper, Dominguez and Frankel (1993) use daily and weekly official and press report data on intervention directed at the yen/dollar and DM/dollar exchange rates between 1984 and 1990 . The authors find that intervention had a significant impact on the exchange rate. Moreover, they find no clear pattern that can help discriminate between the effectiveness of coordinated and noncoordinated intervention. Later studies confirm Dominguez and Frankel's finding that intervention has an impact on exchange rate levels. Using a case study approach for the yen/dollar and mark/dollar exchange rates during the period 1985-91, Catte et al. (1994) find that this result holds particularly for coordinated interventions. However, other papers do not support the conclusion that intervention is effective. Baillie and Osterberg (1997a), for example, find that over the period August 1985 to March 1990, Federal Reserve intervention did not influence the mark/dollar or yen/dollar exchange rates. Zurlinden (1996) looks at the intervention conducted by the Swiss National Bank between 1984 and 1996 and finds no significant impact on the levels of the Swiss franc/DM or Swiss franc/dollar exchange rates.

There is now general consensus in the literature that intervention does not affect exchange rates through the portfolio channel, i.e. by changing the relative outstanding supply of domestic and foreign assets and thereby of the expected relative returns on these assets. ${ }^{3}$ There is some, but no conclusive, evidence that intervention mainly works through the signalling channel, i.e. by the central bank conveying a signal to market participants about information on future fundamentals that they do not have. $^{4}$

3 See, for example, Lewis (1988) and Dominguez and Frankel (1993).

4 Rogoff (1984) is among the first to test the importance of the portfolio balance channel. He finds no significant effects of sterilised intervention through this channel. Dominguez and Frankel (1993), however, find evidence in favour of this channel. 
Over the past few years, attention has shifted to studying the effects of intervention on exchange rate volatility. ${ }^{5}$ Most of these studies have looked at the conditional exchange rate volatility, usually estimated with GARCH models. Empirical evidence suggests that central bank intervention tends to increase the conditional exchange rate volatility. Connolly and Taylor (1994), for example, use a GARCH model to describe conditional yen/dollar volatility and use market data on intervention by the Bank of Japan. They present evidence that, between 1977 and 1979, Bank of Japan intervention was associated with an increase in conditional yen/dollar volatility. Similarly, Baillie and Humpage (1992) find a positive relationship between Federal Reserve, Bank of Japan and Bundesbank intervention and the conditional volatility of the DM/dollar and yen/dollar exchange rates for the period February 1987 to February 1990. Dominguez (1993), however, argues that the impact on exchange rate volatility depends on how central banks conduct intervention. Looking at daily and weekly data for 1985-91, she finds that intervention that is officially announced reduces volatility while intervention that is not detected by the market increases volatility. Finally, Hung (1997) finds that intervention can affect exchange rate volatility through the noise-trading channel, i.e. by inducing noise traders to react to changing market conditions.

In recent years, data on volatility implied by options have been used to study the effect of intervention on market participants' assessments of future exchange rate volatility. ${ }^{6}$ The advantage of implied volatility over measures of volatility computed from actual exchange rate realisations, for example using GARCH models, is that they incorporate a market assessment of future volatility that is not directly observable. The idea here is that intervention on a particular day may send a signal to market participants about the future exchange rate policy and hence influence the market's forecasts of future exchange rate volatility.

The evidence on the impact of intervention on implied volatility is mixed. Bonser-Neal and Tanner (1996) use data on implied volatilities from exchange traded options from 1985 to 1991 together with official data on intervention by the Federal Reserve and the Bundesbank. They also recover data on perceived intervention by the Bank of Japan from newspaper articles. They find that intervention had a different impact on volatility over different time periods. Between February 1987 and December 1989 (the "Louvre period"), intervention actually increased implied volatility, while there is some, although not much, evidence that intervention reduced exchange rate volatility between 1990 and 1991 . Over the period 1985 to 1991 as a whole, there is no evidence that central bank intervention reduced exchange rate volatility. Bonser-Neal and Tanner (1996) also examine whether changes in implied volatility Granger cause intervention by the Federal Reserve and find little evidence of Granger

5 Dominguez (1998) provides a good overview of this literature.

6 The usefulness of implied volatility from currency options as a forecast of future exchange rate movements has been documented in Figlewski (1997) and Béranger et al. (1999). 
causality from implied volatility to intervention. Murray et al. (1996) investigate the effect of different intervention strategies by the Bank of Canada on implied volatility of the Canadian/US dollar exchange rate. In contrast to Dominguez' (1993) results, they find that intervention that was expected or that was unexpectedly light had no effect on implied volatility, while intervention that was unexpected and heavy significantly reduced implied volatility. Dominguez (1998) looks at the effect of intervention on both GARCH volatility and implied volatility. She finds that the effect depends on both the sample period and the intervention strategy. An interesting result is that intervention can lead to an increase in volatility even if market participants do not perceive it. Similarly to Bonser-Neal and Tanner (1996), she also finds that volatility does not Granger-cause intervention.

Edison (1993) and Almekinders (1995) survey empirical work on the determinants of intervention. The approach that is generally followed in the literature consists of specifying and estimating a reaction function for central banks. The objectives being considered include "leaning against the wind", minimising deviations of exchange rates from some implicit target levels and reducing uncertainty. Eijffinger and Gruijters (1991) find that, between 1985 and 1987, the Federal Reserve and the Bundesbank intervened mainly to reduce erratic exchange rate movements and "lean against the wind". Dominguez and Frankel (1993) find that between September 1985 and December 1990 the Federal Reserve and the Bundesbank mainly intervened when the dollar deviated from its implicit targets. They specify these targets based on Funabashi's (1988) analysis of central bank intervention and, alternatively, by assuming that the targets equal the exchange rate level implied by purchasing power parity. A similar conclusion is reached by Goodhart and Hesse (1993) based on an analysis of intra-day data between 9 April and 30 June 1989. Almekinders and Eijffinger (1996) present evidence that, from 1987 to 1989, the Federal Reserve intervened also with the intention of lowering exchange rate uncertainty. Baillie and Osterberg (1997a) find that, between 1985 and 1990, spot exchange rate volatility Granger causes intervention in the yen/dollar market, while the forward premium's conditional volatility does not. They conclude that intervention is motivated by increases in spot rather than forward market volatility.

\section{The data}

\subsection{Data on central bank intervention}

In this paper, we use Reuters press reports as a source for identifying episodes of central bank intervention in the yen/dollar market. ${ }^{7}$ These press reports reveal interventions that are perceived by market participants and hence may not necessarily reveal actual central bank interventions. In

7 Chang and Taylor (1998) have recently used Reuters' reports to identify the occurrence and timing of intervention in the yen/dollar market during the period 1 October 1992 to 30 September 1993. 
addition, Reuters articles may well report cases where market participants thought a central bank was intervening when in fact this was not the case.

Figure 1 shows the yen/dollar exchange rate between 13 September 1993 and April 1996. During this period, traders perceived central bank intervention in the yen/dollar market on 89 days. Forty times central banks were seen intervening on a single day. On twenty occasions market participants spotted interventions that occurred on several day in a sequence. Reuters always provides information on which central banks were observed in the market. On 78 days the Bank of Japan was observed in the market and on 18 days the Federal Reserve was seen to intervene. Traders spotted activity by European central banks aimed at influencing the yen/dollar rate on eleven days.

Figure 1

Yen/dollar spot exchange rate, 1993-96

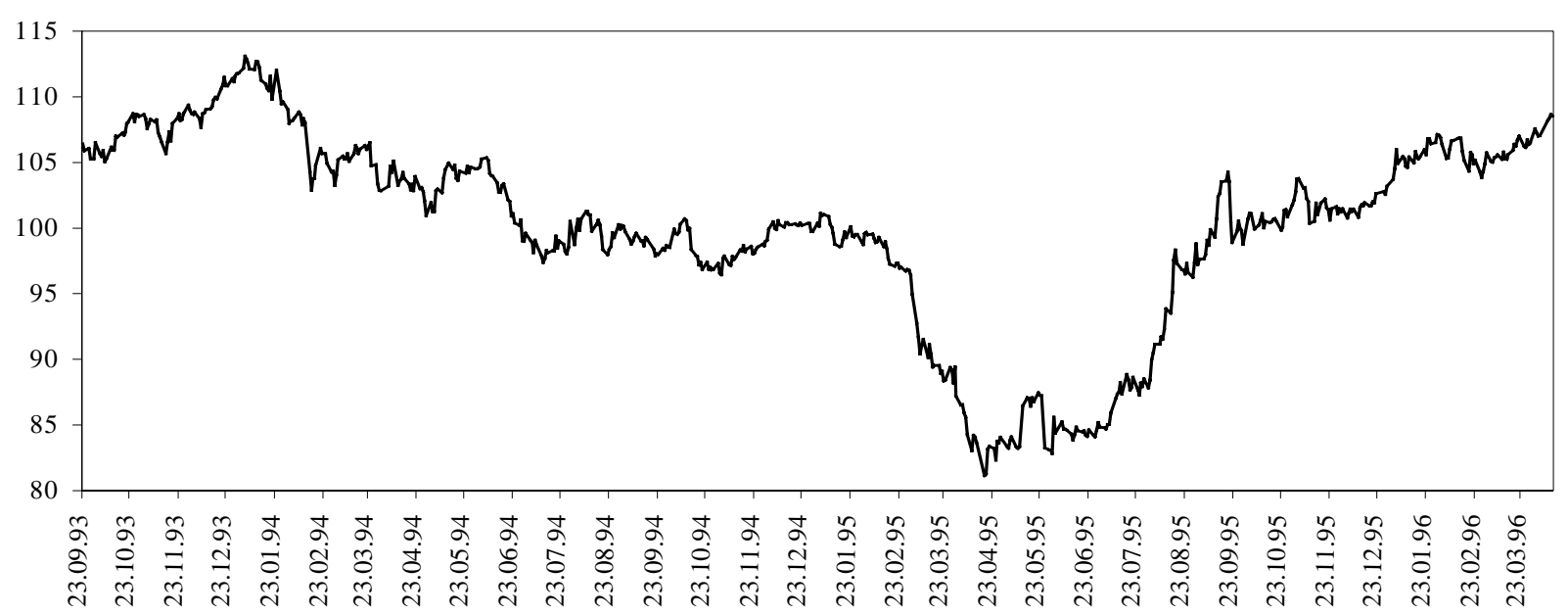

Since the source of information is always mentioned in the Reuters article, it is possible to distinguish interventions that are officially announced from those that are not announced but guessed by the market. Here we classify an intervention as "official" if it was officially announced and as "discreet" otherwise. In most of the cases (on 82 days), intervention was carried out discreetly. Reuters articles also identify market rumours about intervention, i.e. episodes when traders are not sure about whether central banks have intervened or not. In our sample period, this occurred on eight days. ${ }^{8}$

In this paper, we define as concerted intervention those episodes in which two or more central banks were observed in the market on the same day. Fourteen of the 89 perceived intervention episodes fall into this category. Reuters news also generally contain some information on where the intervention was conducted (for example in Tokyo or New York), when and how often (e.g. repeatedly in the

8 In our empirical analysis, we ignore market rumours about intervention. The econometric results in Section 4 are robust to treating market rumours as cases where traders were certain about central bank intervention. 
morning and early afternoon) and how it was conducted (e.g. if it involved an electronic broking system). In many cases, Reuters also reports traders' views on the size of intervention, typically distinguishing transactions involving small or moderate amounts from massive or aggressive intervention. In some cases, traders' estimates of the amounts involved are also reported. Traders at times perceived "light" interventions by the Bank of Japan or the Fed involving amounts as low as $\$ 100$ or $\$ 200$ million. At other times, they commented on interventions they considered "massive", "heavy" or "aggressive", and for which their estimates can range from $\$ 500$ million to several billions of dollars. However, since these estimates are not always reported, in this paper we identify only the days on which intervention was perceived. We also classify interventions according to whether they were "heavy" or "light". We define as "heavy" intervention those episodes in which market participants perceive an aggressive or massive intervention or estimate that intervention involved $\$ 500$ million or more. We classify all other intervention episodes as "light". 9 . During the period under review, 20 interventions were heavy and 69 were light.

It is impossible to gauge the accuracy of traders' perceptions of intervention without comparing them with official data on intervention. While the Federal Reserve has in the past given access to daily data on its interventions, the Bank of Japan does not make its intervention figures publicly available. Previous studies (Dominguez and Frankel (1993), Bonser-Neal and Tanner (1996)) have used official data for Fed interventions and used newspaper articles to build a data set on intervention conducted by the Bank of Japan. ${ }^{10}$ A cross-check with Bonser-Neal and Tanner's data set for the period from January to July 1991 suggests that the Reuters data set used in this paper contains many more intervention episodes than their data set. Out of twelve intervention episodes found in Reuters articles during this period, only three were reported also in newspapers and included in their data set. This suggests that our data set may provide a more complete description of market participants' perceptions of intervention.

\subsection{Option data}

In recent years, data from foreign exchange option markets have been used, assuming risk-neutrality, to extract information about the entire probability density function (PDF) of the underlying exchange rate (BIS (1996 and 1999); Malz (1996); McCauley and Melick (1996a and 1996b)). The four moments of this distribution - the mean, variance, skewness and kurtosis - can be used to characterise market expectations of future exchange rates.

9 We picked $\$ 500$ million as a threshold because, during the period under review, this figure was typically associated by traders with a large intervention.

10 Bonser-Neal and Tanner (1996) show that their reporting of intervention episodes is more complete than Dominguez and Frankel's (1993). 
The mean of a PDF can be interpreted as traders' average expectation of the yen/dollar rate at a future date. Since the PDFs are estimated with the assumption of risk-neutrality, their mean is equal to the forward rate. The variance of a PDF can be interpreted as providing a measure of how uncertain the market is on a given day about the exchange rate that will prevail over the near future. The third moment of a PDF, skewness, can be interpreted as the weight that market participants put on a much higher and a much lower yen/dollar exchange rate in the near future with respect to the forward rate. We define a PDF to be skewed to the left (or negatively skewed) when, compared with the forward rate, market participants assign more weight to a much weaker dollar rather than to a much stronger dollar against the yen. Similarly, we define a PDF as skewed to the right (or positively skewed) when the market attaches more weight to a much stronger dollar than a much weaker dollar in the near future. Kurtosis, the fourth moment of a PDF, measures how "fat" its tails are, and can be interpreted as indicating how likely market participants think very large exchange rate changes in either direction will be in the near future.

It is important to keep in mind that the interpretation of the estimated PDFs is not as straightforward as might be hoped, given that the PDFs capture market views as to the likelihood of particular exchange rate outcomes as well as market preferences towards risk. Unfortunately, in the absence of strong assumptions, it is impossible to distinguish between the two. A simple example illustrates the problem. Suppose we observe an increase in the price of fire insurance. This increase might reflect the market view that fires are now more likely, hence there is a greater need for insurance. Alternatively, the price increase might reflect a change in market sentiment regarding potential exposures in the event of a fire. The probability of a fire may not have increased; however, the market view of any loss associated with a fire may have increased. The observation that the price of insurance has increased does not allow us to determine whether fires are more likely, whether exposure is perceived as larger, or some combination of both. In the same way, a change in option prices does not allow us to separate out changes in views on future exchange rates from changes in potential exposures. However, over a short period, it is perhaps more likely that market views with regard to future exchange rate outcomes will change rather than market preferences towards risk. If this is the case, comparisons of PDFs across time may reveal some information on movements in market views on likely exchange rate outcomes.

For each day from 13 September 1993 to 23 April 1996, the four moments of the risk-neutral PDF of the yen/dollar exchange rate were estimated by applying the method developed by Melick and Thomas (1997) to OTC option prices provided by a large commercial bank in London. The PDFs were estimated using the bank's quotes on the at-the-money implied volatility, the risk reversal and the strangle. The maturity of the options is constant and equal to one month. The three quotes are translated into six option prices (one put and one call for every strike price) in terms of units of yen per 
dollar. The PDF is assumed to be a mixture of two lognormal distributions and is estimated so as to minimise the difference between the observed and the predicted option prices. ${ }^{11}$

Figure 2 shows the times series of estimates of the first two moments of the PDF, the mean and the variance, of the yen/dollar exchange rate. Estimates of the skewness are reported in Figure 3 together with estimates of the mean.

Figure 2

Mean and variance of the probability distributions of the yen against the dollar, 1993-96

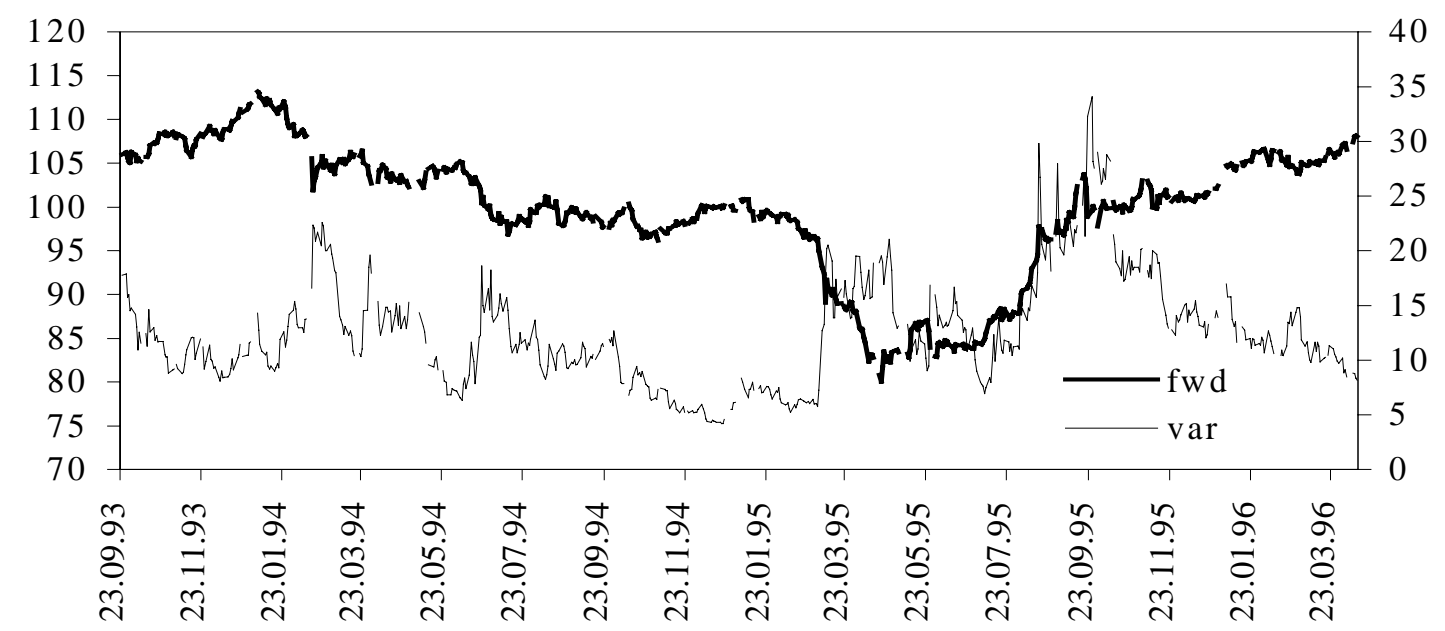

Note: The estimation assumes risk neutrality.

Figure 3

Mean and skewness of the probability distributions of the yen against the dollar, 1993-96

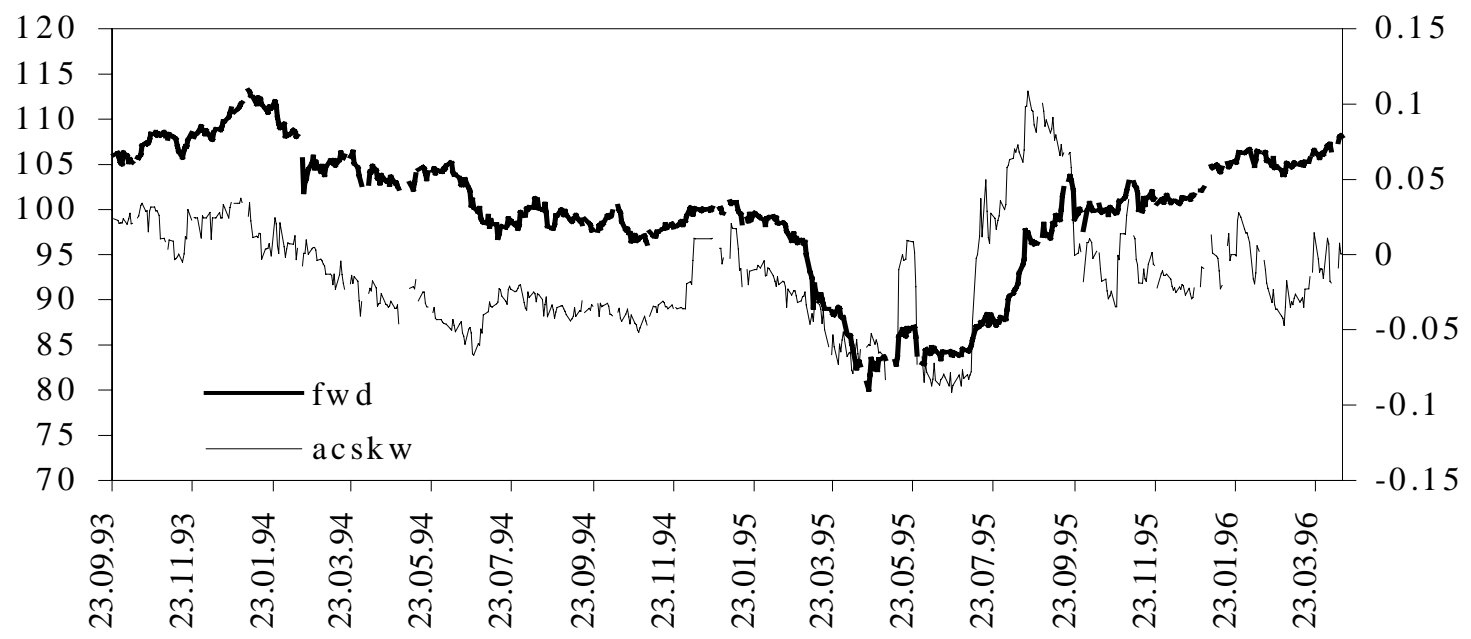

Note: The calculation assumes risk neutrality.

11 For a discussion of the OTC options market see Malz (1996). Melick and Thomas (1997) and McCauley and Melick (1996a) contain further details on the estimation of a mixture of lognormals with OTC options data. 
Figure 4 reports estimates of the fourth moment of the PDF (the kurtosis) over the period September 1993 to April 1996. Since these estimates based on our data set turned out to be quite unreliable, we dropped the kurtosis from our analysis.

Figure 4

Mean and the kurtosis of probability functions of the yen against the dollar, 1993-96

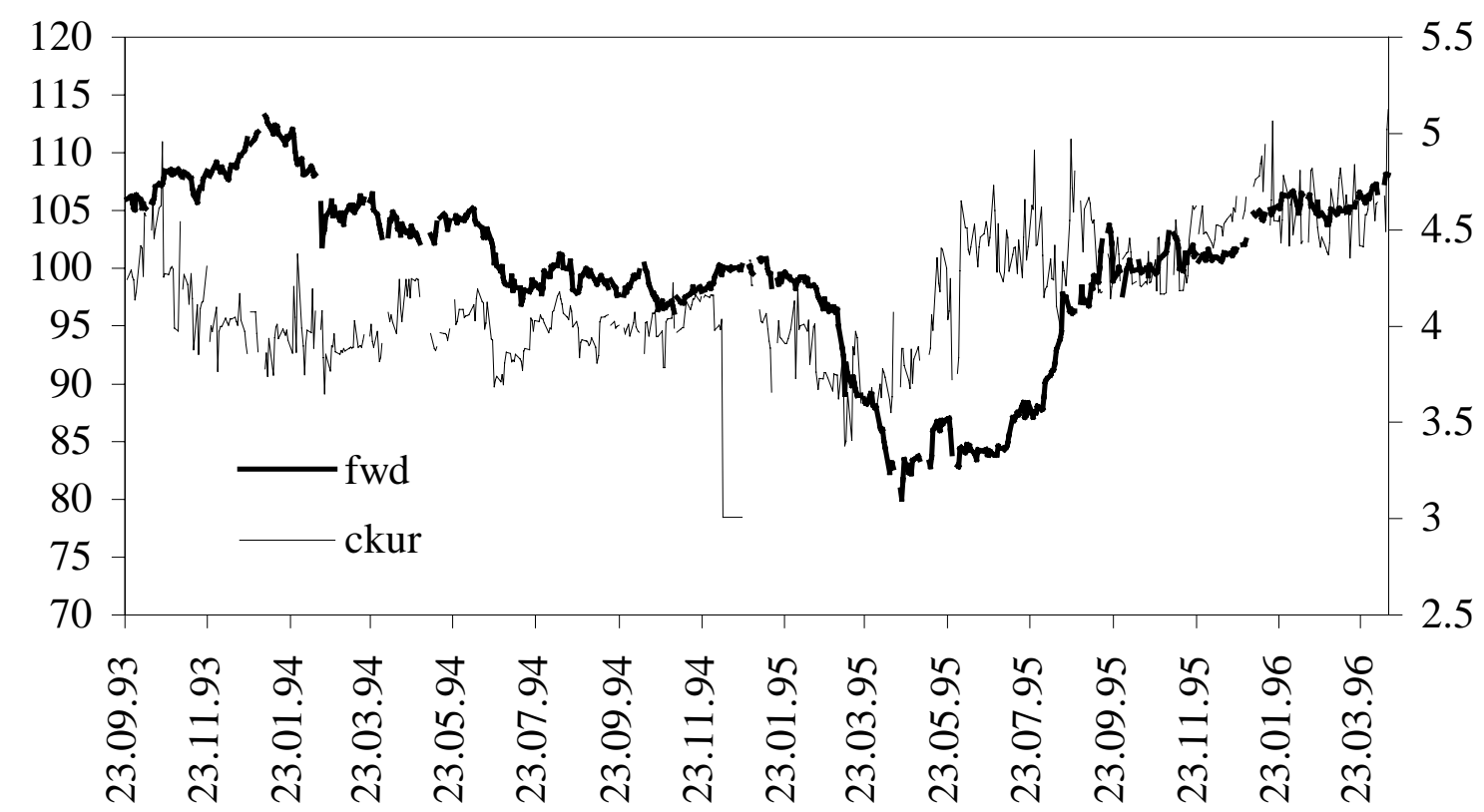

Note: The calculation assumes risk neutrality.

It is necessary to identify correctly the timing of interventions with respect to the time at which the option data are recorded. Given the difference of nine hours between the Asian time zone and GMT, if the Bank of Japan is seen intervening in Asian markets, Reuters will report this before the option prices are recorded in London. In these cases, the timing of the intervention dummy and that of the parameters of the PDFs are set equal in the data set. When intervention occurred on day $t$ in New York, it is introduced at time $t+1$ in the data set because it will be known in London after the option data are reported. In the few cases in which intervention was carried out in Europe, we relied on additional information contained in the Reuters articles to determine whether it was perceived before or after the option prices were recorded. In the empirical part of this paper, we assume that intervention in European markets always preceded the recording of option prices and therefore use the same timing convention that we use for interventions conducted in Asia. ${ }^{12}$

12 Robustness checks show that using a different timing assumption for intervention in Europe does not alter the empirical results in this paper. 


\section{Intervention and market expectations}

Figure 5 illustrates with an example how the analysis of risk-neutral PDFs can be used to analyse the effect of foreign exchange intervention. The episode of concerted intervention by Japanese, German and US authorities on 15 August 1995 has been described as "pushing on an open door" (BIS (1996)). Central banks purchased dollars when the US currency was appreciating against the background of heavy Japanese buying of US bonds and option dealers' hedging.

Figure 5 shows that the PDFs around August 1995 exhibited right skewness, indicating that market participants attached a higher probability to a much stronger rather than a much weaker dollar one month ahead with respect to the forward rate. ${ }^{13}$ Following central bank intervention, the skewness increased on 16 August, suggesting that the concerted action by central banks increased the market bias towards a much stronger dollar. At the same time, the variance of the PDFs rose on 16 August 1995. It then declined during the following days. This can be interpreted as indicating that intervention was followed by a temporary increase in market uncertainty. Moreover, the kurtosis of the PDFs increased on the day that central banks intervened, suggesting that the concerted effort to boost the already appreciating dollar induced market participants to attach more weight to the possibility of further very large changes of the yen/dollar exchange rate in either direction in the following month. ${ }^{14}$

Figure 5

\section{Probability distributions of the yen against the dollar}

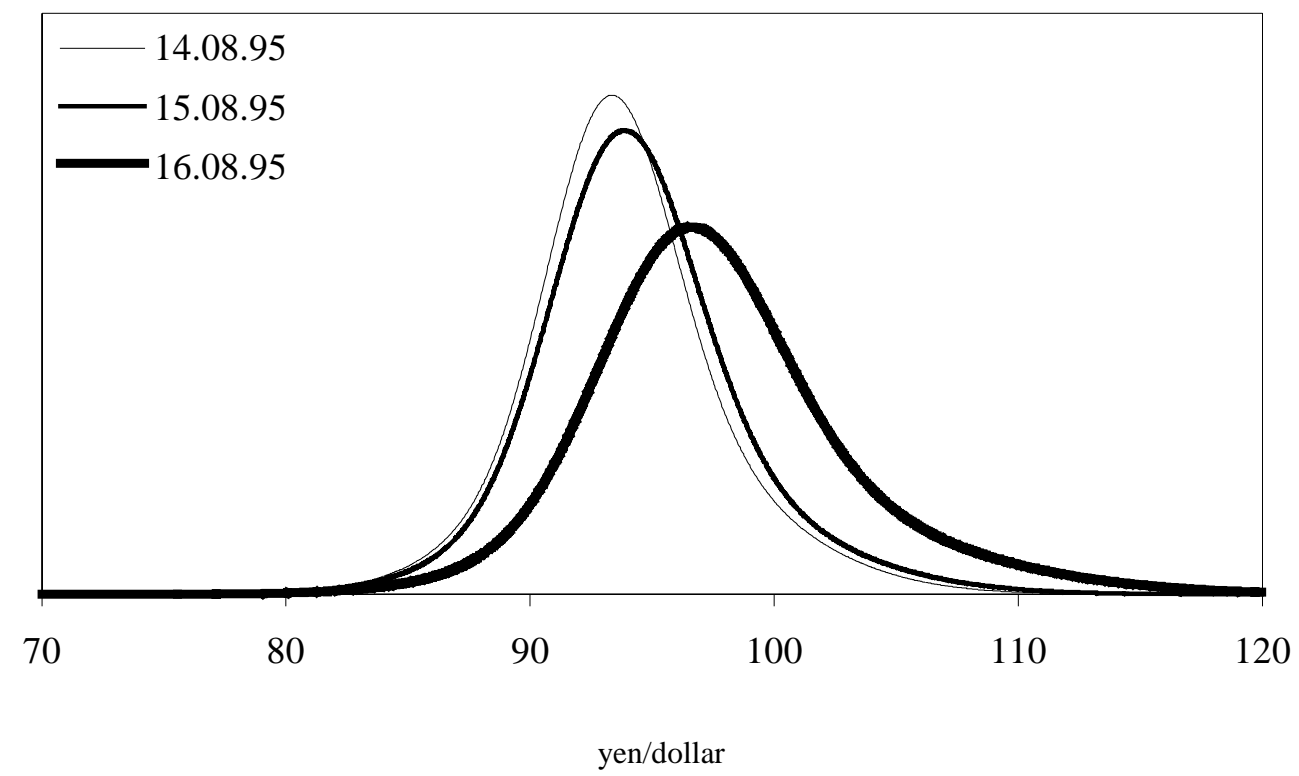

Note: The calculation assumes risk neutrality.

13 The PDFs in Figure 5 are expressed in yen per dollar.

14 Given the caveat on the estimation of the kurtosis, this statement has to be taken with caution. 
Figures 6-8 provide some information on the average movements of the mean, variance and skewness of the risk-neutral PDFs around intervention episodes over the period from 13 September 1993 to 23 April 1996. For each day up to 20 days before and 20 days after intervention, Figure 6 shows the mean of the risk-neutral PDF, i.e. the forward rate, averaged over all intervention episodes. ${ }^{15}$ Figures 7 and 8 show averages of the variance and the skewness, respectively.

Figure 6

Mean of the PDFs of the yen against the dollar around all perceived intervention episodes Averages over 89 episodes of dollar purchases, 1993-96

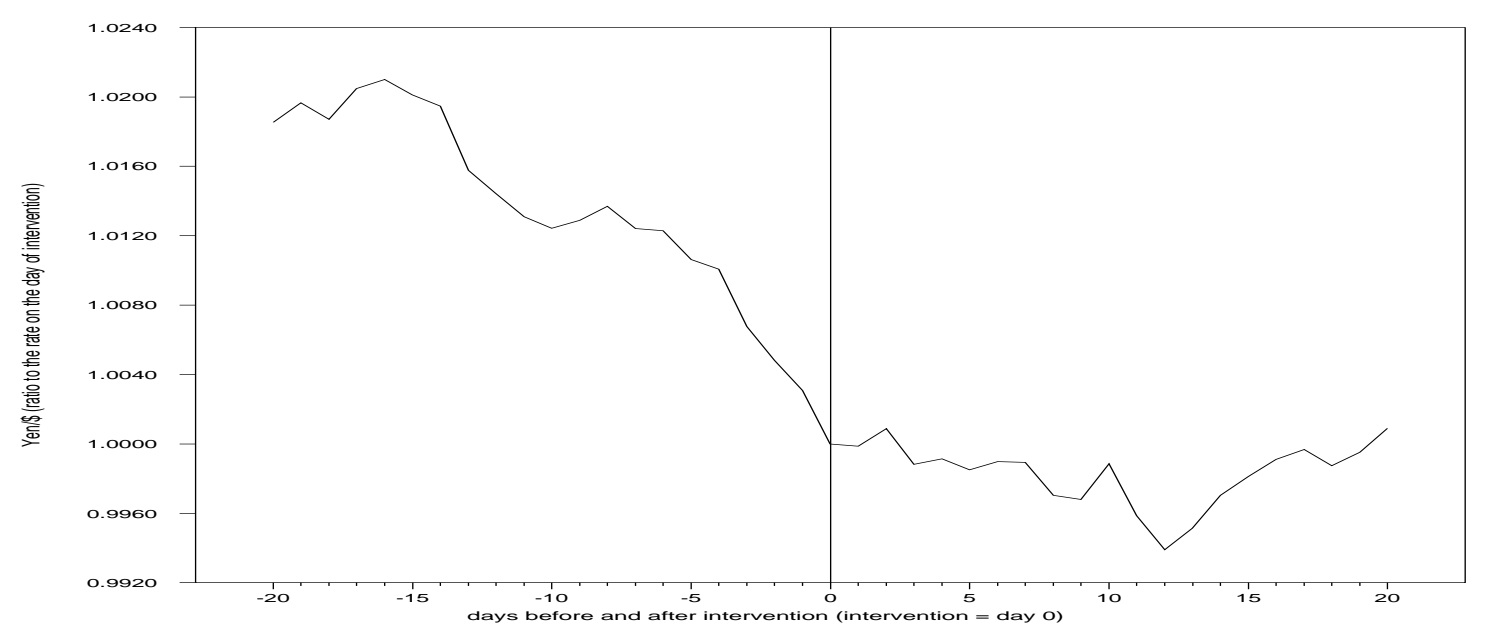

Figure 7

Variance of the PDFs of the yen against the dollar around all perceived intervention episodes Averages over 89 episodes of dollar purchases, 1993-96

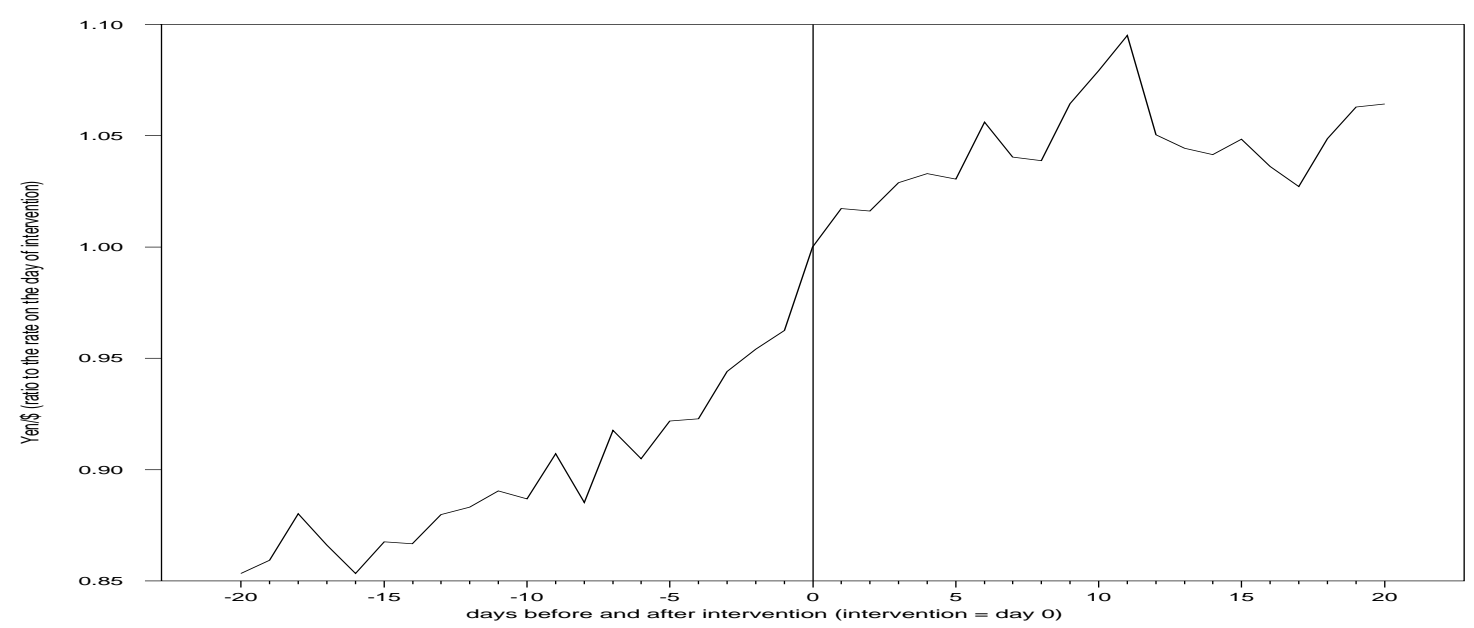

15 The chart looks very similar when, instead of the mean of the PDF, i.e. the forward rate, we use the spot rate. 
Figure 8

\section{Skewness of the PDFs of the yen against the dollar around all perceived intervention episodes}

Averages over 89 episodes of dollar purchases, 1993-96

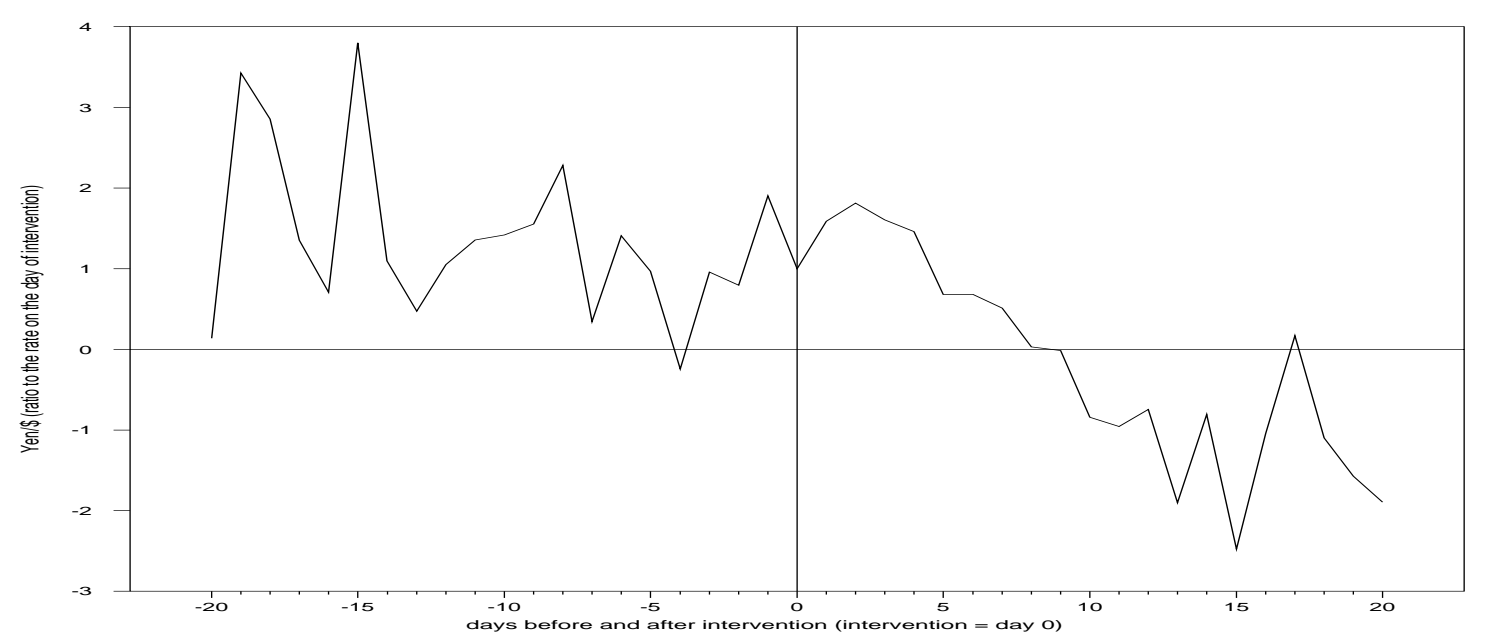

While these graphs are certainly interesting, one should be careful in using them to draw inferences about the impact of intervention for two main reasons. First, on the day that central banks intervene, other important macroeconomic or policy news may arrive that could prompt market participants to react. For example, the announcement of an unexpectedly high industrial production figure for Japan could induce traders to revise their expectations of future Japanese interest rates upwards, thereby boosting the yen. Intervention could also be carried out on the same day on which a participating central bank changes its monetary policy rate. The behaviour of the moments would then reflect the effect of both the arrival of macroeconomic or policy news and central bank intervention. The simple averages reported in Figures 6-8 do not allow disentangling the influence of these different factors.

A second shortcoming of these graphs is that intervention could be carried out on several successive days. As a consequence, the average values of the PDF moments on day $t$ could reflect not only the effect of intervention that occurred on that day, but also the effect of central bank actions carried out on previous days.

In order to assess the effect of intervention and control for these two issues, we therefore used daily data to estimate regression equations that explain each moment in terms of current and lagged intervention and a set of other explanatory variables. To distinguish the effect of intervention from the effect of news about relevant macroeconomic variables that may arrive on the same day, we included a set of variables that measure the unanticipated component of announcements of major macroeconomic variables. A novelty of our set of news variables is that it includes not only variables for the United States, as in all previous studies on intervention in the yen/dollar market, but also variables for Japan. 


\subsection{The simultaneity problem}

Regressions that estimate the effect of central bank intervention on market conditions face a potential simultaneity problem. In a regression of the variance of the expected exchange rate on an intervention dummy, for example, a positive coefficient can mean either that intervention increases expected volatility, or that central banks intervene to smooth rising exchange rate volatility, but are not successful.

A simple example can be used to illustrate this problem. Consider the case where a central bank intervenes to smooth volatility. To simplify the exposition, we ignore here the role of other moments of the PDF. In its simplest form, we can then write the following system of equations:

$$
\begin{aligned}
& M_{t}=a_{1}+a_{2} I_{t}+a_{3} X_{t}+\varepsilon_{t} \\
& I_{t}=b_{1}+b_{2} M_{t}+b_{3} Y_{t}+\eta_{t}
\end{aligned}
$$

where $M_{t}$ measures the variance of the PDF, $I_{t}$ captures intervention, and $X_{t}$ and $Y_{t}$ represent other factors that influence volatility and intervention. $\varepsilon_{t}$ and $\eta_{t}$ are error terms.

Estimating the effect of intervention on the variance implies estimating the coefficient $a_{2}$ in the first equation, while the effect of the variance on intervention is captured by the coefficient $b_{2}$. This would require solving the simultaneous system for $M_{t}$ and $I_{t}$ in terms of $X_{t}, Y_{t}$, and $\varepsilon_{t}$ and $\eta_{t}$. If standard OLS procedures are applied to estimate these two equations separately, they will yield biased and inconsistent estimates of $a_{2}$ and $b_{2}$ because $\operatorname{cov}\left(I_{t}, \varepsilon_{t}\right) \neq 0$ and $\operatorname{cov}\left(M_{t}, \eta_{t}\right) \neq 0$.

A method that has been used in the literature to address this simultaneity problem consists in lagging the intervention variable by one period in the first equation and then estimating that equation directly with OLS. ${ }^{16}$ However, this method will misrepresent the true effect of intervention on market expectations because part of this effect may already be captured in lagged values of the dependent variable (the moment) which are introduced among the explanatory variables. It was therefore chosen to deal with the simultaneity bias by using an Instrumental Variables (IV) estimator. Following previous work that used this approach, we used estimates of a reaction function for the Federal Reserve and the Bank of Japan as instruments for actual intervention. ${ }^{17}$

Consider the following regression equation:

16 Studies that followed this method include Dominguez (1993), Bonser-Neal and Tanner (1996) and Murray et al. (1996).

17

Baillie and Humpage (1992) and Almekinders and Eijffinger (1991) followed this method for Federal Reserve and Bundesbank intervention. As an alternative method we could have chosen a Full Information Maximum Likelihood (FIML) estimator, which, unlike the Instrumental Variables estimator, is efficient. We decided, however, against using the FIML estimator because, unlike the IV estimator, it is very sensitive to specification errors in one of the equations of the system. 


$$
M_{t}^{j}=a+\sum_{i=1}^{5} b_{i} \times M_{t-i}^{j}+\sum_{i=0}^{5} c_{i} \times I_{t-i}+\sum_{i=0}^{5} d_{i} \times X_{i}+\varepsilon_{t}
$$

where $M_{t}^{j}$ is the $j$-th moment at time $t, I_{t}$ is a dummy that takes the value one on day $t$ if intervention occurred on that day and zero otherwise, $X_{t}$ is a vector of macroeconomic variables and $\varepsilon_{t}$ is an error term. Instead of estimating equation (3) using OLS, we instrumented intervention with a reaction function for the Federal Reserve and the Bank of Japan $I N T^{*}$ and estimated the equation

$$
M_{t}^{j}=a+\sum_{i=1}^{5} b_{i} \times M_{t-i}^{j}+\sum_{i=0}^{5} c_{i} \times I N *_{t-i}+\sum_{i=0}^{5} d_{i} \times X_{i}+\varepsilon_{t}
$$

\subsection{Estimates of a reaction function for the Federal Reserve and the Bank of Japan}

The method we follow to estimate reaction functions builds on the work by Baillie and Osterberg (1997a). In their study of the behaviour of the Federal Reserve and the Bank of Japan, they find that the probability of the two central banks intervening is determined by the deviation of the exchange rate from some "target" nominal exchange rate level and by the volatility of the exchange rate. In the postBretton Woods era, the Federal Reserve and the Bank of Japan have never officially announced a target for the yen/dollar exchange rate. However, Funabashi (1988) argues that they adopted some implicit target levels for the nominal exchange rates. Baillie and Osterberg (1997a) take the target levels for the nominal exchange rates from Funabashi (1989).

Here we assume market participants believed that the Federal Reserve and the Bank of Japan decided to intervene when the spot rate, the variance or the skewness deviated from what the market considered to be some implicit target ranges. We also assume the likelihood of intervention depended on the distance from these targets. We choose implicit targets for the spot exchange rate based on press reports. ${ }^{18}$ As a first approximation, we set the targets for the higher moments equal to their historic average. In other words, we assume that central banks tended to intervene whenever the variance or skewness of market expectations were abnormally high or low with respect to their historical average.

Since we use a dummy variable to capture intervention, we choose a Probit model to represent the reaction function for central banks, which explains the intervention variable by the various PDF moments lagged by one day. We estimate the Probit model

$$
P\left(I_{i}=1 \mid X_{i}\right)=\Phi\left(M_{j} \beta_{j}\right)
$$

\footnotetext{
${ }^{18}$ An alternative approach used in the literature consists of setting the implicit target equal to the PPP value of the yen/dollar exchange rate, as in Dominguez and Frankel (1993). Other studies have set the target rate equal to past levels of the exchange rate, thereby assuming that central banks systematically "lean against the wind" (Almekinder and Eijffinger (1991)).
} 
where $\Phi$ is the standard Normal cumulative density function. It is estimated by maximising the loglikelihood function

$$
L=\sum I_{i \neq 0} \log \Phi\left(M_{j} \beta_{j}\right)+\sum I_{i=0} \log \Phi\left(M_{j} \beta_{j}\right)
$$

The explanatory variables include the distance of the yen/dollar spot rate from the bottom of the target range when the exchange rate is below that limit (yenldis). In principle, we could also have introduced a variable for the case in which the exchange rate breaks through the top of the target range. In practice, since perceived intervention during our sample period always involved dollar purchases, the top of its target range was irrelevant. We also include the distance of the variance from its historical average when the dollar is, respectively, appreciating (dvarcha) or depreciating (dvarchd). Furthermore, a variable is introduced to measure the distance of skewness from its historical average when the yen is depreciating and the market is skewed towards a much weaker yen (dskewchd). Similarly, we use a measure of the distance from the average of skewness when the yen is strengthening and the market is biased towards a much stronger yen (dskewcla).

Overall, our specification of the reaction functions performs quite well. The model is correct in $90 \%$ of the cases for the Federal Reserve and in $81 \%$ of the cases for the Bank of Japan. Table 1 reports the coefficients, t-statistics and significance levels of the Probit models for the two central banks.

Table 1

Probit estimates for the Federal Reserve and Bank of Japan reaction functions

\begin{tabular}{|l|ccc|ccc|}
\hline \multirow{2}{*}{ Variable } & \multicolumn{3}{|c|}{ Federal Reserve } & \multicolumn{3}{c|}{ Bank of Japan } \\
\cline { 2 - 7 } Constant & Coefficient & t-statistic & Signif. level & Coefficient & t-statistic & Signif. level \\
yenldis & -2.40 & -11.34 & 0.00 & -1.33 & -15.69 & 0.00 \\
dvarcha & -0.51 & -0.39 & 0.70 & 0.23 & 4.00 & 0.00 \\
dvarchd & -10.32 & -0.05 & 0.96 & 0.04 & 1.09 & 0.27 \\
dskewchd & -4.33 & -0.04 & 0.96 & 0.02 & 0.26 & 0.80 \\
dskewcha & 26.66 & 1.73 & 0.08 & -0.62 & -0.08 & 0.93 \\
\hline
\end{tabular}

Note: The table reports coefficients of a Probit model estimated separately for the Federal Reserve and the Bank of Japan. It is estimated with daily data over the period 13 September 1993 to 23 April 1996.

Table 1 brings out some interesting results about what market participants considered to be the intervention strategies by the Federal Reserve and the Bank of Japan. The Probit results differ markedly for the two central banks. The most important variable in the reaction function of the Federal Reserve is the deviation of skewness from its historical average when the yen is depreciating and the market is skewed towards a much weaker yen. The coefficients on all the other explanatory variables are not statistically significant. This suggests that, during the period 1993-96, market participants thought that the Federal Reserve intervened in support of the dollar mainly when market conditions looked most appropriate, i.e. when the dollar was appreciating and market participants were attaching 
a greater weight to a much stronger dollar in the near future. It should be stressed, however, that this result is driven to a large extent by those episodes in which the Federal Reserve intervened in concertation with other central banks. The intervention episode on 15 August 1995 described above can be viewed as an application of this strategy. These results contrast with the reaction functions estimated for the Federal Reserve for earlier periods by Dominguez and Frankel (1993) and Goodhart and Hesse (1993). Our results are in line with the common observation that the Federal Reserve changed its strategy in the 1990s and became much less active in FX markets than it was previously (Bonser-Neal and Tanner (1996)).

The insignificant coefficient on the variance of the PDFs is consistent with Bonser-Neal and Tanner's (1996) finding that implied volatility does not Granger cause the Federal Reserve's intervention. It suggests that, on average, the Federal Reserve was not viewed by traders to intervene to reduce uncertainty in FX markets. This contrasts with Baillie and Osterberg's (1997a) conclusion that, during the period 1985 to 1990 , increases in exchange rate volatility tended to prompt the Federal Reserve, the Bank of Japan and the Bundesbank to purchase dollars for yen or mark.

Our results suggest that, between 1993 and 1996, market participants viewed the Bank of Japan as behaving very differently from the Federal Reserve. The coefficient on the spot rate in the Probit regressions for the Bank of Japan is positive and highly significant. By contrast, the coefficients on all the other variables are not statistically significant. This indicates that traders viewed the Bank of Japan as intervening mainly when the yen/dollar rate deviated from what they perceived to be some implicit target ranges. This conclusion is consistent with the study by Gaiotti et al. (1989), who find that, from 1973 to 1987, the Bank of Japan reacted to deviations of the yen/dollar rate from implicit target levels. One explanation of the more pro-active approach followed by the Japanese authorities is that, unlike the US authorities, they were subject to more pressures from the private sector during this period to react to the strength of the yen. It is likely that the incentives for the Japanese authorities to intervene would be different in an environment in which the yen was depreciating.

Finally, we find no evidence that traders viewed the Bank of Japan as intervening on average to reduce market uncertainty. This finding confirms Bonser-Neal and Tanner's (1996) result that implied volatility does not Granger cause intervention by the Bank of Japan.

\subsection{The effect of intervention on market expectations}

To investigate the effect of intervention on market expectations, we estimate equation (4) for the mean, the variance and the skewness of the PDFs using daily data from 13 September 1993 to 23 April 1996. We address the simultaneity problem described above by using the Probit estimates of the reaction functions of the Federal Reserve and the Bank of Japan as instruments for intervention. The instruments take the value one whenever the reaction function of either the Federal Reserve or the Bank of Japan takes the value one, and zero otherwise. 
Among the explanatory variables, we also include a number of variables that capture the effect of news about macroeconomic or policy developments that may arrive on the same day on which intervention is carried out. We measure the unexpected component of news by the difference between official data announcements and the results of opinion surveys conducted during the days preceding the announcements by Money Market Services. Unlike previous studies, we introduce news variables not only for the United States but also for Japan. For the United States, we include news about the CPI, the PPI, industrial production, the unemployment rate and the trade balance. For Japan, we include news about Tankan surveys, retail sales, industrial production, the trade balance and the job offers/seekers ratio. In addition to these news variables, we also introduce the differential between Japanese and US short-term interest rates among the explanatory variables to represent the influence of all other macroeconomic factors. ${ }^{19}$ We also introduce a dummy variable to capture day-of-the-week effects, since there is evidence that asset prices follow intra-weekly patterns. ${ }^{20}$

When the dependent variable is either the mean or the variance, it enters the regression equation in difference of $\operatorname{logs}$ form because both series are non-stationary. Since each moment exhibits persistence, we include lagged values of the moment among the explanatory variables. In addition to lags of the dependent variable (also in difference of logs form), the lagged level is then also included to take account of the possibility of the dependent variable not having a unit root. In the regression equations for the variance, all explanatory variables are expressed in absolute values, as it is assumed that their effect on intervention depends only on their size but not their sign. ${ }^{21}$ We use Newey and West's asymptotic method to obtain correct standard errors in the presence of autocorelated errors.

Table 2 summarises the results. For each equation, it reports the coefficient on contemporaneous intervention and the cumulative sum of coefficients on contemporaneous and lagged intervention.

In the regression equation for the mean of the PDF, the coefficient on current intervention is not statistically significant. This suggests that, on average during the period 1993 to 1996, perceived intervention in support of the dollar had no statistically significant, contemporaneous effect on the expected yen/dollar rate (i.e. the forward rate). Moreover, the cumulative sums of current and lagged intervention are not statistically significant, suggesting that, even over time, intervention had no significant impact on the forward rate.

Consistent with the results for the mean of the PDFs, we find that, on average, perceived intervention had no significant impact on the skewness of the PDFs, i.e. on markets participants' balance of risks

19 The short-term interest rate differential has been commonly used in previous studies, such as Dominguez (1993) or Murray et al. (1996)

20 For reasons of space, the estimation results for these variables are not presented here.

21 For our intervention variable, it is not necessary to take absolute values in the regressions for the variance, as all interventions perceived during our sample period were in the same direction (dollar purchases against yen). 
between a much stronger and a much weaker dollar against the yen one month ahead. As for the regression for the mean, we do not find evidence of a significant contemporaneous effect of intervention, nor any effect over time.

Table 2

Estimates of the effect of intervention on PDF moments

\begin{tabular}{|c|c|c|c|c|c|}
\hline & & Lag & Coefficient & Statistic & Signif. level \\
\hline \multirow[t]{7}{*}{ Mean } & Joint significance & & & 17.52 & 0.01 \\
\hline & Sums of coefficients & 0 & -5.14 & -1.12 & 0.26 \\
\hline & & 0 to 1 & -3.96 & 0.37 & 0.54 \\
\hline & & 0 to 2 & -9.30 & 0.63 & 0.43 \\
\hline & & 0 to 3 & 3.78 & 0.09 & 0.77 \\
\hline & & 0 to 4 & 13.25 & 0.77 & 0.38 \\
\hline & & 0 to 5 & 6.57 & 0.18 & 0.67 \\
\hline \multirow[t]{7}{*}{ Variance } & Joint significance & & & 14.52 & 0.02 \\
\hline & Sums of coefficients & 0 & 0.21 & 1.86 & 0.06 \\
\hline & & 0 to 1 & 0.29 & 6.24 & 0.01 \\
\hline & & 0 to 2 & 0.32 & 5.34 & 0.02 \\
\hline & & 0 to 3 & 0.40 & 6.04 & 0.01 \\
\hline & & 0 to 4 & 0.57 & 7.19 & 0.01 \\
\hline & & 0 to 5 & 0.56 & 6.37 & 0.01 \\
\hline \multirow[t]{7}{*}{ Skewness } & Joint significance & & & 25.96 & 0.00 \\
\hline & Sums of coefficients & 0 & -3.91 & -0.95 & 0.34 \\
\hline & & 0 to 1 & -7.84 & 1.98 & 0.16 \\
\hline & & 0 to 2 & -6.91 & 0.76 & 0.38 \\
\hline & & 0 to 3 & 3.86 & 0.22 & 0.64 \\
\hline & & 0 to 4 & 6.13 & 0.23 & 0.63 \\
\hline & & 0 to 5 & 6.64 & 0.26 & 0.61 \\
\hline \multicolumn{6}{|c|}{$\begin{array}{l}\text { Note: The table reports the estimation results for equation (3). The equation is estimated separately for the mean, the } \\
\text { variance and the skewness of the PDFs over the period } 23 \text { September } 1993 \text { to } 13 \text { April } 1996 \text { using daily data. For the } \\
\text { coefficient on current intervention, the t-statistic is reported in the fifth column. For the cumulative sums of coefficients, } \\
\text { the fifth column reports the F-statistic. }\end{array}$} \\
\hline
\end{tabular}

In the equation explaining the variance of the PDF, the coefficients on current and the first lag of intervention are positive and statistically significant. The sum of coefficients on current and five lags of intervention is also positive and statistically significant. These results suggest that, on average, following intervention that is observed by market participants, the uncertainty prevailing in the market about future exchange rate movements increased. This result is consistent with Dominguez'(1998) finding for the period 1977 to 1994. It is also consistent with Bonser-Neal and Tanner's (1996) finding for the period 1987 to 1989 , but not for their results for the period 1990-91. ${ }^{22}$

22 The coefficient estimates in the regression for the kurtosis turn out to have very large standard errors, reflecting the difficulty of accurately estimating the kurtosis of the PDF with our OTC option price data set. 


\section{Conclusions}

This paper presents empirical evidence on the relationship between central bank intervention that is perceived by traders and reported in the press and market expectations of the yen/dollar exchange rate. We look at the period 13 September 1993 to 23 April 1996. During this period, all central bank intervention in the yen/dollar market was directed at supporting the dollar. The paper uses the moments of the expected distribution of future exchange rates, which are estimated from option prices, as a way to describe market expectations. It also uses a new data set on intervention episodes perceived by market participants, which is based on Reuters reports. The paper looks both at how market expectations affected the likelihood of central bank intervention and at the impact of intervention on market expectations.

We find that market participants perceived the Bank of Japan and the Federal Reserve to be following different intervention strategies during the period 1993 to 1996. We find evidence that traders viewed the Bank of Japan as responding mainly to deviations of the spot exchange rate from what they considered to be implicit target ranges. We find little evidence that traders expected it to intervene to reduce market uncertainty. By contrast, the Federal Reserve was viewed to have mainly intervened in support of the dollar when market conditions seemed to be most conducive to a successful intervention, i.e. when the dollar was appreciating and market views were tilted in favour of a much stronger dollar. The intervention episode on 15 August 1995 is an example of this strategy.

Consistent with the findings of some of the literature, the regression analysis suggests that, on average, perceived intervention in support of the dollar had no statistically significant effect on the forward rate (the mean of the PDF). In particular, we do not find evidence of a contemporaneous impact of intervention on the forward rate, nor any deferred effect. Consistent with the results for the forward rate, we do not find evidence that, on average, perceived intervention influenced the skewness of the PDFs. In other words, intervention did not influence the balance of weights that market participants assign to a future sharp appreciation and a sharp depreciation of the dollar against the yen, but not on the same day.

An important finding is that, between September 1993 and April 1996, the existence of a market perception of central bank intervention directed at the yen/dollar exchange rate was associated with a higher variance of expected future spot rates. This suggests that perceived central bank intervention may on average have increased the uncertainty prevailing in the market regarding future movements in the spot rate. 


\section{References}

Almekinders, Geert J (1995): Foreign Exchange Intervention. Theory and Evidence. Edward Elgar.

Almekinders, Geert J and Sylvester Eijffinger (1996): “A friction model of daily Bundesbank and Federal Reserve intervention”. Journal of Banking and Finance, Vol. 20, pp. 1365-80.

Baillie, Richard and Owen Humpage (1992): "Post-Louvre intervention: Did target zones stabilise the dollar?" Federal Reserve Bank of Cleveland Working Paper No. 9203.

Baillie, Richard and William P Osterberg (1997a): "Why do central banks intervene?" Journal of International Money and Finance, Vol. 16, No. 6, pp. 909-19.

Baillie, Richard and William P Osterberg (1997b): "Central bank intervention and risk in the forward market". Journal of International Economics, Vol. 43, pp. 483-97.

Bank for International Settlements (1996): 66th Annual Report.

Bank for International Settlements (1999): Estimating and Interpreting Probability Density Functions. Proceedings of the workshop held at the BIS on 14 June 1999.

Béranger, Florence, Gabriele Galati and Kostas Tsatsaronis (1999): "The information content of implied volatility from currency options". Mimeo, BIS.

Board of Governors of the Federal Reserve (1994): "Treasury and Federal Reserve foreign exchange operations". Federal Reserve Bulletin, July.

Board of Governors of the Federal Reserve (1995a): "Treasury and Federal Reserve foreign exchange operations". Federal Reserve Bulletin, June.

Board of Governors of the Federal Reserve (1995b): "Treasury and Federal Reserve foreign exchange operations". Federal Reserve Bulletin, December.

Bonser-Neal, Catherine (1996): "Does central bank intervention stabilize foreign exchange rates?" Federal Reserve Bank of Kansas City Economic Review.

Bonser-Neal, Catherine and Glenn Tanner (1995): "Central bank intervention and the volatility of foreign exchange rates: Evidence from the options market". Journal of International Money and Finance, Vol. 15, No. 6, pp. 853-78.

Catte, Pietro, Giampaolo Galli and Salvatore Rebecchini (1994): "Concerted interventions and the dollar: An analysis of daily data", in Kenen, Papadia and Saccomanni (eds.) The International Monetary System, Cambridge University Press, Cambridge.

Chang, Yuanchen and Stephen J Taylor (1998): "Intraday effects of foreign exchange intervention by the Bank of Japan". Journal of International Money and Finance, Vol. 17, pp. 191-210.

Connolly, Robert and William Taylor (1994): "Volume and intervention effects of yen/\$ exchange rate volatility, 1977-1979", in Advances in Financial Planning and Forecasting, Vol. 5, JAI Press, Greenwich, Connecticut.

Dominguez, Kathryn (1993): "Does central bank intervention increase the volatility of foreign exchange rates?” NBER Working Paper No. 4532.

Dominguez, Kathryn (1998): "Central bank intervention and exchange rate volatility". Journal of International Money and Finance, Vol. 17, pp. 161-90.

Dominguez, Kathryn and Jeffrey Frankel (1993): "Does foreign exchange intervention work?" Institute for International Economics, Washington.

Edison, Hali (1993): "The effectiveness of central bank intervention: A survey of the literature after 1982”. Princeton University Special Papers in International Economics No. 18. 
Figlewski, Stephen (1997): "Forecasting volatility". Financial Markets, Institutions \& Instruments, 6 (1), New York University Salomon Center.

Funabashi, Yoichi (1988): Managing the Dollar: From the Plaza to the Louvre. Institute for International Economics, Washington.

Gaiotti, E, P Giucca and S Micossi (1989): "Cooperation in managing the dollar (1985-87): Interventions in foreign exchange markets and interest rates". Banca d'Italia, temi di discussione del servizio studi, No. 119, June.

Goodhart, Charles A E and T Hesse (1993): "Central bank forex intervention assessed in continuous time". Journal of International Money and Finance, Vol. 12, pp. 386-9.

Hung, Juann H. (1997): "Intervention strategies and exchange rate volatility: A noise trading perspective". Journal of International Money and Finance, Vol. 16, No. 5, pp. 779-93.

Klein, Michael and Karen Lewis ( 1991): "Learning about intervention target zones". National Bureau of Economic Research Working Paper, No. 3674.

Lewis, Karen (1988): "Testing the portfolio balance model: A multi-lateral approach". Journal of International Economics, 24 (February), pp. 109-27.

Malz, Alan (1996): "Over-the-counter currency option markets". Mimeo, Federal Reserve Bank of New York.

McCauley, Robert and William Melick (1996a): "Risk reversal risk". Risk, Vol. 9, No. 11, November.

McCauley, Robert and William Melick (1996b): "Propensity and Density". Risk, Vol. 9, No. 12, December.

Melick, William and Charles Thomas (1997): "Using option prices to infer PDFs for asset prices: An application to oil prices during the gulf crisis". Journal for International Money and Finance.

Murray, John, Mark Zelmer and Des McManus (1996): “The effect of intervention on Canadian dollar volatility". Mimeo, Bank of Canada.

Rogoff, Kenneth (1984) "On the effects of sterilized intervention: an analysis of weekly data". Journal of Monetary Economics, Vol. 14, September.

Zurlinden, Mathias (1996): "Devisenmarktinterventionen der Schweizer Nationalbank 1986-1994". Quartalsheft SNB, 2/96. 




\section{Recent BIS Working Papers}

No.

61

November 1998

62

March 1999

63

March 1999

64

March 1999

65

April 1999

66

April 1999

67

May 1999

68

May 1999

69

June 1999

70

June 1999

71

June 1999

72

August 1999

73

August 1999

74

August 1999

75

August 1999

76

October 1999
Foreign direct investment and employment in the industrial countries

The pricing of bank lending and borrowing: evidence from the federal funds market

Microeconomic inventory adjustment and aggregate dynamics

Precarious credit equilibria: reflections on the Asian financial crisis

Higher profits and lower capital prices: is factor allocation optimal?

Evolving international financial markets: some implications for central banks

The cyclical sensitivity of seasonality in US employment

The evolution and determinants of emerging market credit spreads in the 1990s

Credit channels and consumption in Europe: empirical evidence

Interbank exposures: quantifying the risk of contagion

The term structure of announcement effects

Reserve currency allocation: an alternative methodology

The Taylor rule and interest rates in the EMU area: a note

The dollar-mark axis

A note on the Gordon growth model with nonstationary dividend growth

The price of risk at year-end: evidence from interbank lending
Author

P S Andersen and $\mathrm{P}$ Hainaut

Craig H Furfine

Jonathan McCarthy and Egon Zakrajšek

Joseph Bisignano

P S Andersen, M Klau and $\mathrm{E}$ Yndgaard

William R White

Spencer Krane and William Wascher

Steven B Kamin and Karsten von Kleist

Gabe de Bondt

Craig H Furfine

Michael J Fleming and Eli M Remolona

Srichander

Ramaswamy

Stefan Gerlach and

Gert Schnabel

Gabriele Galati

Henri Pagès

Craig H Furfine 